\title{
Understanding the UK Hospital Supply Chain in an Era of
}

\section{Patient Choice}

\author{
Authors: M. Bourlakis, F. Clear, L. Patten
}

Dr Michael Bourlakis*, Senior Lecturer, Brunel University, Business School, Elliot Jacques Building, Uxbridge, Middlesex, UB8 3PH, United Kingdom, Telephone: +44 (0) 1895265427

Email: Michael.bourlakis@brunel.ac.uk

Fintan Clear, Lecturer, Brunel University, Business School, Elliot Jacques Building, Uxbridge, Middlesex, UB8 3PH, United Kingdom, Telephone: +44 (0) 1895265235

Email: fintan.clear@brunel.ac.uk

Louise Patten, Brunel University, Business School, Elliot Jacques Building, Uxbridge, Middlesex, UB8 3PH, United Kingdom, Email: louisepatten@btopenworld.com

* Corresponding Author 


\begin{abstract}
The purpose of this paper is to investigate the UK hospital supply chain in light of recent government policy reform where patients will have, inter alia, greater choice of hospital for elective surgery. Subsequently, the hospital system should become far more competitive with supply chains having to react to these changes as patient demand becomes less predictable. Using a qualitative case study methodology, hospital managers are interviewed on a range of issues. Views on the development of the hospital supply chain in different phases are derived, and are used to develop a map of the current hospital chain. The findings show hospital managers anticipating some significant changes to the hospital supply chain and its workings as Patient Choice expands. The research also maps the various aspects of the hospital supply chain as it moves through different operational phases and highlights underlying challenges and complexities. The hospital supply chain as discussed and mapped in this research is original work given there are no examples in the literature that provide holistic representations of hospital activity. At the end, specific recommendations are provided that will be of service to managers, researchers and policy makers.
\end{abstract}

\title{
Keywords
}

Elective Surgery, Hospital Supply Chain, NHS England, Patient Choice, Qualitative Case Study Methodology. 


\section{BIOGRAPHIES}

Dr Michael Bourlakis: Dr Michael Bourlakis is a Senior Lecturer at Brunel Business School. Michael previously held academic positions at Newcastle University, Oxford Institute of Retail Management at Templeton College, Oxford University and Leicester University Management Centre. Michael has published over 120 papers in numerous journals, books, conference proceedings and other academic and professional outlets. Michael is an Editorial Board Member of five academic journals such as the Supply Chain Management: An International Journal, the British Food Journal, the Journal of Chain and Network Science, the International Journal of Cooperative Management, the International Journal of Economic Sciences \& Applied Research. He is also the Coordinating Editor for the International Journal of Business Science \& Applied Management (www.business-andmanagement.org). He is a Committee Member of the European Technology Platform "Food for Life" program (European Union) and the Academic Logistics Research Network of the Chartered Institute of Logistics and Transport (UK). His main research interests focus on supply chains, food logistics and marketing channels.

Fintan Clear: With an academic background in Geography and Communications Policy, Fintan worked in business communications for GKN, Pitman, the European Space Agency (ESA) and the BBC World Service before moving into systems development with Sainsbury's where he gained extensive experience of the large supply chain systems. Moving into higher education, he helped set up electronic business degrees and developed a research focus in technology adoption, especially amongst small firms. He has worked on many funded research projects including a pan-European project on virtual working and HEIFsponsored projects looking at ICT adoption and 'Web 2.0' tool use by firms and their role in 
knowledge transfer and growth. He is also looking at the potential role that theatric devices can play in the knowledge transfer of complex knowledge. He is a member of the Institute of Knowledge Transfer, the British Academy of Management and BRESE (Brunel Research in Enterprise, Innovation, Sustainability and Ethics).

Louise Patten: Louise Patten has over 25 years of clinical and managerial experience in the NHS. She undertook her Registered Nurse training at Southampton University Hospital, specialising in Coronary Care before moving to several London Hospitals. After completing her District Nurse Diploma in Oxford Brookes University, she went on to take a degree in Health Science at Leicester University. Moving into NHS management, she won the HSJ Award for overall best project (Enhanced Home Support) and was selected to take the first ever Health Service Management Centre's Pathfinder N.H.S. Leadership Initiative. After holding posts as Associate Director of Nursing, Primary Care Commissioner and Deputy Chief Executive of a Primary Health Care Trust, Louise took her MBA at Brunel University, achieving the prize for best post-graduate dissertation. She now works as a Healthcare Management Consultant. 


\section{INTRODUCTION}

Health services are subject to regular government reform in the UK. The most recent reform agenda includes 'Patient Choice' which is intended to allow patients greater choice of hospitals for their elective care (Department of Health 2006a). Such a policy is designed to act as a lever for improving the quality and performance of the National Health Service (NHS) in England (Burge et al. 2005) which naturally has implications for the efficient and effective workings of health care supply chains. For example, Prime Minister Tony Blair highlighted some intended outcomes of the 'Patient Choice' agenda: "Choice mechanisms enhance equity by exerting pressure on low-quality or incompetent providers. Competitive pressures and incentives drive up quality, efficiency and responsiveness in the public sector. Choice leads to higher standards." (cited in Appleby et al. 2003). Apparent political certainty is not matched however by definitive illustration of hospital operations. Though research into hospital activity shows the inherent complexities of such supply chains (see for example Towill \& Christopher 2005), there appears to be no holistic illustrations of mapped hospital supply chains. Furthermore, there appears to be no universal set of mapping conventions to facilitate an understanding of supply chains and their management in any industrial context (Gardner \& Cooper 2003; Mentzer 2004). Thus, patient choice and hospital supply chain mapping issues are the focus of this paper. We begin with a brief analysis of the literature on hospital supply chains and follow this with a discussion of the NHS hospital system and the latest UK government reforms targeting the NHS in England. The methodology employed is then outlined and this leads on analysis of the empirical findings. The paper concludes with recommendations for further research and policy development. 


\section{LITERATURE REVIEW}

\section{The Hospital Supply Chain}

Supply Chain Management (SCM) is described by Christopher (1998) as "the management of upstream and downstream relationships with suppliers and customers to deliver superior customer value at less cost to the supply chain as a whole”. Effective supply chain management is seen as key to maintaining an organisation's competitiveness (Saunders 1997; Mentzer 2004). This is because potentially any activity within the supply chain can affect costs due to the interrelatedness of the different actors within the chain. Nevertheless, an overarching emphasis on cost and the 'lean' paradigm of supply chain working (Womack et al. 1990) with predictable demand patterns, high sales volumes and low product variety (Christopher 1998) may appear ill-suited to healthcare service delivery where availability of service is an imperative. So an 'agile' paradigm of supply chain working is recognised as offering the necessary flexibility in healthcare delivery. Such an approach is designed to accommodate unpredictable demand including low volumes per individual 'product' and high levels of 'product' variety (Christopher and Towill 2000). This inherent flexibility sees 'agility' defined as "a business-wide capability that embraces organisational structures, information systems, logistics processes and, in particular, mindsets" (Christopher and Towill 2000: p. 206). These writers observe that the concept of a pipeline might be better suited to the discussion of health care than a 'supply chain' as such, and point out that healthcare pipelines require not only the organisational "how" skills of supply chain management but also the "what" skills of clinicians (Towill and Christopher 2005).

A large literature has grown up over the last 20 years examining the theory and practice of supply chain management but according to McKone-Sweet et al. (2005), there is a limited 
academic literature that addresses the challenges unique to healthcare. Nevertheless, in the relatively small literature examining hospital supply chains, there is general agreement within the corpus that hospital supply chains and their management is complex (Fenies et al. 2006; Colletti 1994; Jarrett 1998, Schneller \& Smeltzer 2006, MacVaugh 2007). Sourcing of goods and services from a host of suppliers in combination with the delivery of services to patients with a wide range of health requirements is a challenge made more complex by the need for some hospitals to provide both planned and emergency care. This mix of planned and contingent services leads to hospitals being 'relatively inefficient' due to the expense of equipping and operating such 'multi-activity hospitals' and as the result of the considerable 'interference' between elective and emergency treatment (Towill \& Christopher 2005).

\section{Echoing the emergence of MRP (Material Requirements Planning) and MRP II}

(Manufacturing Resource Planning) in the industrial domain of the 1980s and 1990s, many of the studies on hospital supply chain management to date are in fact directed at the processes and improvements that can be achieved in materials management (Jarrett 1998, DacostaClaro 2002, Heinbuch 1995, Rivard-Royer et al.. 2002, Minahan 2007). A key area of materials management for hospitals is that of just-in-time (JIT) inventory control that requires precise co-ordination of demand and supply deliveries which, though physically possible, is difficult to achieve in hospitals due to the mix of emergency and planned care as noted. It is worth noting that 'out-of-stock' items in health care can imply qualitatively different outcomes than those in a standard industrial setting - for example the shortage of drugs or blood types might directly lead to patient deaths. Knight et al.. (2005) and Harland \& Knight $(2001 \mathrm{a}, \mathrm{b})$ examine supply networks in the public sector in studies that are primarily concerned with the 'harder' supply chain components. Nevertheless, there appears to be relatively little research on such material management techniques within the UK National Health Service (NHS). 
Subsequently, a number of researchers argue for the general transposition of methods from the industrial sphere, notably from manufacturing, into healthcare as means of creating efficiencies and helping to provide high quality service. For example, Young (2005) promotes the use of 'process philosophies' in healthcare delivery, and advances 'lean thinking', the 'theory of constraints' and 'Six Sigma' as methods that could be applied in a clinical setting (Young et al. 2004). Others argue for the use of modelling tools and cite a large number of 'industrial' methods with potential application in healthcare delivery (Kuljis et al. 2007). However, there are inhibiting factors to the use of these 'service improvement' tools. For example, Towill and Christopher $(2003,2005)$ point to knowledge deficiencies and stress that logistics and supply chain management concepts and their practice are lacking in the UK Hospital system. Kuljis et al. (2007) stress the value of human engagement and note that for modelling tools to be successfully applied, all healthcare stakeholders need to be incorporated in their use as integral elements. Adequate incorporation of all stakeholders cannot be assured however if the findings of Addicott and Ferlie (2007) were to hold true beyond the case studies they explore. For example, they find that fighting and power plays between senior and junior clinicians serve to inhibit communications and optimal decisionmaking in what they describe as 'managed clinical networks'.

\section{THE UK HOSPITAL SYSTEM}

At the apex of the NHS hierarchy is the Department of Health (DoH) which devolves strategic responsibility for healthcare provision to Strategic Health Authorities (SHAs). A number of Primary Care Trusts (PCTs) work under each SHA to commission health care for a local population. This will include hospital services as delivered by NHS Hospital Trusts (including District Hospitals which traditionally provide generalist care for its local 
population and Tertiary Hospitals which provide specialised care for more complex health problems) and Foundation Trust Hospitals (independent public benefit organisations that provide services for NHS patients according to NHS principles and standards). Financed by the UK Treasury, funds are passed through the DoH to the SHAs and on to PCTs in annual budgets accounting for the healthcare needs of a resident population including community and all hospital care. The challenge of meeting these needs has been achieved in part through the central management of treatment decisions and prescribing practices of a PCT's General Practitioners (GPs). Overall, a general practitioner (GP) is a medical practitioner who provides primary care to his/her patients and is their first point of contact for most medical services in the NHS whilst careful monitoring of the activity is provided by the hospital sector.

With the intention of 'safeguarding the NHS for the next 20 years' (Department of Health, 2000), UK Government reforms aim to move the NHS further away from a centrallycontrolled 'supplier push' system towards a more distributed 'demand pull' model in which a multiplicity of providers compete to offer services that are commissioned locally. In this way, clinicians and patients are seen as having a more active role in local service development and in the choice of service provider. In this vein, several inter-related policies are now in the process of being implemented into NHS operations. These include 'Payments by results', 'Practice-based commissioning', use of 'Independent providers and Foundation Trusts' and 'Patient Choice' (Department of Health 2006c). Additionally, an 18-week target extending from the point of GP referral to the delivery of hospital treatment has been set for elective healthcare from 2008 (Department of Health 2006c). These reforms are designed to change significantly the manner in which healthcare service providers operate in England, and have the potential to significantly affect patterns of demand experienced by hospitals. 
In the past, block contracting arrangements were negotiated in advance between PCTs and local District Hospitals in an environment where the majority of patients received their general healthcare at their local hospital. Linked directly to the annual forecast of planned hospital activity, demand for elective healthcare was managed through (often lengthy) waiting lists, with quarterly adjustments for under- or over-performance. Planning for hospital service delivery was a relatively straightforward task therefore with internal supply chain and capacity requirements based upon relatively predictable historical data of patient activity (once demographic changes were taken into account). Such dependable activity flows assured income to local hospitals for a common range of planned healthcare activities. However this approach offered little incentive for system efficiencies (Street 2006).

Since 2005 the hospital funding system has been moving incrementally to an activity-based costing $(\mathrm{ABC})$ framework called 'Payment by Results' $(\mathrm{PbR})$ in which 'money follows patient', a remuneration system evident in other European countries and North America (Department of Health 2005). Hospitals receive a payment-per-activity at a nationally-fixed tariff with rewards for volumes of work adjusted for differences in case mix. The $\mathrm{PbR}$ framework is designed to ensure a much greater tally between hospital income and the actual level of healthcare activity undertaken on site. This provides incentives for hospitals to increase their healthcare activity and to reduce the length of inpatient stay in order to generate increased patient throughput and as a result greater income. Nevertheless, a PbR system poses significant challenges to healthcare commissioners in budget management terms. While block contracting assured the hospital a total contract value for a set amount of activity in advance, under $\mathrm{PbR}$ there is no such guarantee; hospitals are paid only for activity undertaken. In this case, the emphasis for hospital managers shifts away from managing supply contracts for health services to managing the demand for health services. 
Patient Choice aims to allow patients a greater choice of hospital for their elective care (Department of Health 2006a). Previously, patients were added to the waiting list of their local district hospital where they waited until it had the capacity to admit and treat. Now patients can choose from at least four providers including NHS and independent hospitals for 14 health specialities. Research on Patient Choice highlights some key factors which influence patients when making a choice of hospital. Length of waiting list has been found to be a major factor in patients' choice of hospital (Rosen et al. 2007, Burge et al. 2005, Page \& Byrom 2005, Coulter et al. 2005). Rosen et al. (2007) found that approximately $20 \%$ of patients waiting more than six months for an operation opted for a provider other than their local hospital when offered a choice. When Coulter et al. (2005) surveyed 2,144 patients, $67 \%$ of those who were offered a choice, chose to go to a different hospital, while those in pain or whose local hospital had a poor reputation were more likely to choose an alternative provider. National Patient Choice Surveys (Department of Health 2006b) cite hospital location or transport considerations as being the most frequently cited factors that patients take into account when making a choice of hospital. Propper et al. (2006) found that patients living in areas of deprivation travelled significantly less far than other patients; such a finding has implications on the equity of healthcare provision.

General Practitioner roles in patient choice are highly influential. The study by Rosen et al. (2007) of GP views on their role in patient choice found that most GPs make healthcare choices on their patient's behalf, a finding affirmed by Isroliwala et al. (2004). Department of Health findings $(2006 a, b)$ show that GPs remain the most popular individual to assist patients. PbR and Patient Choice facilitate the government's aim to open up the healthcare market place by a funding method that follows the patient wherever they choose to be treated. At the same time, this creates significant problems for healthcare planners in setting 
anticipated health treatment activities for their hospitals which in turn creates problems in supply chain planning.

As all hospitals have had to comply with the 18-week waiting times directive from March 2008, the removal of this factor in a patient's choice of hospital has had the potential to significantly affect the types of healthcare activity undertaken by hospitals and to challenge the effective management of the hospital supply chain. Faced with a plethora of choice and minimum waits, the fear is that patients may become more demanding, less loyal and less predictable (Rhyne 1988). Knight et al. (2005) note that patients are highly influential actors with the potential to destabilise the supply chain. Burge et al. (2005) expand on the research noted above by citing the range of factors that will have an impact on patient choice of provider. These include aspects intrinsic to a particular hospital such as performance (e.g. waiting times, average length of patient stay, MRSA rates, etc), facilities (e.g. availability of car parking, quality of food, etc) and reputation of consultants, and extrinsic factors such as distance from the patient's home, travel times and travel costs.

The challenge for hospitals with the advent of Patient Choice is that it will become harder to predict demand and to manage supply, yet the increased competition means that supply must become more efficient. This research therefore will describe the main actors within a hospital supply chain and will map the supply chain processes against the patient pathway to create a model that is understood by supply chain managers and clinicians. It will then explore the possible effects that Patient Choice will have on the hospital supply chain and make recommendations that will ensure patients retain their right to choice and NHS hospitals retain their future business. Therefore, the following research objectives are identified:

- To establish what hospital managers believe are the key factors for patients when making a choice of hospital; 
- To establish what hospital managers believe are the main actors, activities and inputs within the hospital supply chain;

- To illustrate what hospital managers believe in terms of the potential impact of expanded Patient Choice on the hospital supply chain.

\section{METHODOLOGY}

A qualitative case study methodology is employed in this research. Case studies enable a detailed inquiry into a specific situation using extensive study of a single issue from a variety of different sources (White 2000). It also enables the researcher to gather rich knowledge of a specific context (Yin 1984) and this is particularly relevant in this study as we aim to understand and explain the effects of a policy development (Patient Choice) within a specific environment. In addition, case studies generate empirical data (White 2000) so the research is not dependent purely on work that is already published, especially given there is a restricted literature on this topic. The qualitative approach enables more insightful data to be collected where explanation rather than statistical measurement is required (Bryman and Bell 2003). As part of the empirical work, managers were interviewed from Hospital Trusts serving a population of approximately 1.6 million within the same Strategic Health Authority. The Director of Operations was interviewed who then recommended other senior managers within operational functions so that a fuller picture of strategy and practical supply chain opinion was developed. Primary data collection was undertaken through semi-structured, face-to-face personal interviews from these "key informants" who provided their "expert views" for the topic in hand. We did not interview any other senior managers in these hospitals (e.g. finance, human resources etc) as we felt that these managers who were involved with the hospital operations, were more knowledgeable to address the research objectives. Subsequently, high quality data was generated on three areas of hospital manager perceptions: 
(1) The key factors that are important to patients when making a choice of a hospital.

(2) The main actors, activities and inputs within the hospital supply chain.

(3) The potential impact of expanded Patient Choice on the hospital supply chain.

In principle, interviews are a useful form of data collection as they enable the researcher to be face-to-face with the interviewee and to explain or reword complex questions. These interviews can therefore offer a quality of response that is specific to hospital management and more specialist than random selection of hospital staff or the public. A degree of confidentiality and anonymity was guaranteed to managers which was important given the political nature of the subject as Patient Choice is a core element in current UK's Government - (Labour Party General Election manifesto 2001, see for example http://www.labour-party.org.uk/manifestos/2001/2001-labour-manifesto.shtml). Interviews were conducted in the individual manager's office, ensuring privacy and offering a familiar environment. A total of nine interviews were conducted, each lasting around 60-90 minutes. This is a sufficient number of interviews considering the political nature of the topic and the fact that these managers are very senior professionals who had many difficulties committing time towards our research. In order to establish an illustrative model of a hospital supply chain, managers were shown a basic process map diagram. This map was developed, based on the extensive and senior healthcare experience commanded by one of the authors of this paper. On top of this, relevant secondary data material such as government reports and journal papers supported its development. Interview questions were referred to the map and as the interview progressed, amendments would be noted and the model adjusted accordingly. This map is then a pre-determined model that was used as a useful starting point for visualisation, and was a time-effective method of discussing detailed processes. Miles \& Huberman (1994) describe qualitative research as a form of enquiry requiring an intuitive 
approach to analysis. Answers were sorted into themes under each of the research objectives and quotes used to illustrate specific findings and to provide further value in defining, supporting or elaborating the researcher's interpretation of events (Glaser and Strauss 1967). Data was analysed by content on a question by question basis aiming to produce a big picture map (see Rother and Shook 1998). This map provided a 'skeleton' of the current and forthcoming state of the hospital system (including different phases) and concentrated upon specific flows. A range of Value Stream Mapping tools and techniques were considered for this big picture skeleton including process activity mapping, supply chain response matrix, production variety funnel, quality filer mapping, demand amplification mapping, decision point analysis and physical structure mapping (see Hines and Rich 1997); at the end, the authors made use of process activity mapping. In addition, data triangulation was employed to further improve the validity of the research (Tyler 2004) and this was achieved through an analysis of secondary patient data and the primary data from the nine hospital managers. In the next section, findings for the supply chain process mapping are presented. Revealed in stages, this enables an understanding of the Patient Pathway to be gradually developed.

\section{FINDINGS}

Research was undertaken at three NHS Hospital Trusts within two UK counties and from the same SHA. The Hospitals were approximately 20-30 miles away from one another and there was some minimal overlap of patient catchment areas. Table 1 gives some background data for each of the three.

\footnotetext{
"Insert Table 1 About Here"
} 
Research Objective 1: To establish what hospital managers believe are the key factors for patients when making a choice of hospital

All the nine managers interviewed were very clear on what they believed were the most important factors patients would take into account when choosing a hospital for their elective procedure. For example, all managers believed that patients would act according to GP recommendation, a factor not mentioned in other surveys (see Page \& Byrom 2005). All managers felt that GPs are highly influential with their patients in terms of choosing a hospital for their elective procedure. For example:

"As a patient, you sit in shock as your GP says you have to have an operation. S/he then says you have a choice of hospital; you will automatically ask them what they think" (Operations Manager).

Other factors cited are similar to those found in national patient surveys. All managers felt that hospital reputation was important and four believed this would become more relevant with expansion of Patient Choice and as patient awareness increased. Cleanliness was believed to be quite important due to current media coverage. Age was believed to be a key factor in whether catchment areas might change with Patient Choice. Managers at one of the hospitals in our research, which enjoys a higher than average elderly population, believed they would experience little change to catchment area:

"Our elderly population means we have $80 \%$ market share of activity locally. Older people don't wish to travel; it's as simple as that. Their friends and family are here" (Operations Manager)

All managers believed that patient flows would be mostly affected in the under 65 year age group, citing reluctance to travel as the main reason for anticipating that their older patient flows would be retained. Affluence was cited by five managers at two of the three hospitals 
as having relevance in choice of hospital. As a Director of one of these two hospitals observed:

"Our younger population is affluent and mobile. They think nothing of going 10 miles to Tesco or 30 miles to the outlet centre so of course they'll travel for hospital treatment! We're kidding ourselves if we think it's not going to change" (Director).

Research Objective 2: To establish what hospital managers believe are the main actors, activities and inputs within the hospital supply chain

All managers interviewed were given a copy of an outline hospital supply chain modelled on the patient pathway (Figure 1) and the findings are set out in three stages: Pre-operative, admission \& procedure, and post-procedure. The map attempts to capture the 'patient experience', that is, a patient's interactions with the hospital from the beginning to the end of their elective procedure episode. On the right of the map the consultant team and the relevant boxes demonstrate the key areas of the supply chain that are prescribed by clinicians and therefore under the control of the medical team. The inputs for these supply chains have not all been established yet and so hospital managers were asked to determine where and when inputs were required. Inputs to the left of the patient pathway are under the control of hospital managers and denote the 'hard' components of the supply chain. Arrows show where these inputs have a key integral role in delivering patient care.

\section{"Insert Figure 1 About Here"}




\section{General Practitioner as Gatekeeper}

All managers emphasised the importance of GPs as gatekeepers to NHS services for their patients. Their role was considered critical given patients are screened by GPs before referral. The managers thus described a 'demand-pull' model where demand was initiated through GPs with the hospital responding by then 'pulling' appropriate supplies and services. Without this gatekeeper, the managers noted that:

"Patients self-referring would be a nightmare; there would be little control over the level of severity of a condition, so we'd have the responsibility of telling the patient they don't need admitting because their GP should be managing the condition” (Operations Manager).

Six managers described how GPs are telephoning or emailing consultants for advice regarding patient management, when historically such patients would have been sent in to outpatients for an appointment:

"In order to keep patients out of hospital and avoid tariff, GPS are calling or emailing consultants, seeking advice that was previously given via a letter after the outpatient appointment. We need to start charging for this" (Director).

The development of enhanced primary care for patients as an alternative to hospital care has thus produced an additional supply chain pathway of knowledge exchange between GPs and Consultants. 
In general, a 'Clinical Assessment Centre'(CAC) should not be confused with a 'Clinical Assessment and Treatment Service' (CATS) which are also funded by PCTs but are provided by the independent sector and which typically offer a wide range of minor treatments (including surgery) for orthopaedic conditions, gynecology, urology, audiology, ophthalmology, and ear, nose and throat (ENT) problems.

More specifically, Clinical Assessment Centres (CACs) are a recent innovation in UK healthcare that offer an intermediate level of service for some PCTs between a GP surgery and a hospital. Their role is to make a clinical assessment of the needs of patients referred to them by GPs perhaps by use of further diagnostic tests. In the past, such referrals would have made directly to hospital consultants. With the use of a CAC, the object for the PCT is to ensure some level of consistency across its domain of referrals on to a hospital for elective care treatment and as a means of controlling demand. The findings show, however, that CACs are not perceived as beneficial by all. For one thing it was noted that the specialties offered by CACs were not consistent in regard to all hospitals. Also, as opposed to streamlining elective healthcare, CACs were seen as an additional step in patient flow with the capacity to delay the process of GP referral to outpatient appointment without necessarily lowering related hospital costs:

“(CACs) will always be an extra step - we still send patients through outpatients, because we'll receive the (Payment by Results) tariff. We could reduce outpatient flows but CACs have not taken enough work out of the system to enable us to reduce our consultant teams we still have all those costs" (Director). 
One manager felt that the apparent streamlining offered by CACs would leave neither the clinician nor the patient content:

"The long term plan is to go from CACs to admission, but Consultants are unhappy about that. And did anyone ask patients? Will they be happy to be told they're on a Surgeon's list who won't see them until they're on the operating table? I don't think so!" (Operations Manager).

In addition, six managers were concerned that because CACs (and GP Specialist Clinics) offered choice away from the patient's GP, this could lead to the patient choosing differently, thus creating changes to the hospital's regular activity history. It is worth clarifying that the GP Specialist Clinics involve GPs with advanced knowledge and skills in a particular medical field (e.g. dermatology) and can hold clinics in their specialism.

\section{Outpatients}

In general, 'Outpatients' refers to hospital departments and their clinics to which patients are referred by GPs for clinical advice or treatment. Attendance at 'outpatients' does not generally require an overnight stay at a hospital. 'Outpatients' was seen as important for internal supply chains both in terms of it presenting a first opportunity for Consultants to examine, diagnose and determine treatment, but also as the most visible part of a hospital in marketing terms. As a Director explained:

“Outpatients is our 'front of house'. It needs to be well-staffed, with no waits for scans or diagnostics and provided in a clean, calm, efficient environment. Patients will then choose to come here" (Director). 
Efficient administration of outpatients was believed to be an important influence on patient opinion. Five managers felt that GPs may influence patients adversely if hospital test results undertaken by outpatient clinics on behalf of the GP - were consistently late or inaccurate. The prospect of external diagnostics and treatment centres were not currently perceived to be a threat to outpatient flows given managers at all three hospitals believe that patients and GPs would prefer a hospital and its specialist equipment rather than a smaller clinic:

“Economies of scale don't make sense (in diagnostic \& treatment centres); what if the patient has an ultrasound that shows a serious condition? They need specialists on site to advise and support” (Operations Manager)

\section{Pre-operative assessment}

The research found that pre-operative assessment was an important step in hospital supply chain management as it determined suitability of the patient for the procedure. In addition, five managers believed it to be important in detailing specific patient needs or equipment for the planned procedure.

\section{Changes to process map}

Figure 2 shows changes to the pre-admission stage as a result of the interviews with the managers.

1. The patient pathway was adjusted to account for extra assessment steps including the Clinical Assessment Centre or GP Specialist clinics and the pre-operative assessment.

2. The knowledge exchange from Consultant to GP was added as 'telephone/virtual advice'.

3. Soft components of the supply chain under the aegis of the consultant team (diagnostics, etc) were given arrows to denote where in the pre-admission process they have a key role. 


\section{"Insert Figure 2 About Here"}

\section{(ii): Admission and Elective Procedure}

The research found that two groups of components could be identified in the internal supply chain: those controlled by the Consultant team (Clinical Staff, Diagnostics, Pathology and Pharmacy) and those controlled by hospital managers (beds, IT systems, facility services, administration).

\section{Clinical Staff}

Five managers believed that clinical staff should be differentiated between specialists (such as junior doctors and Nurse Practitioners working under a Consultant) and those with more generic abilities. Taken together, they could offer some operational flexibility. As a Director observed:

"Our Medical Director has a vision that wards should become open to all specialties so we can be as flexible as possible to meet demand. This could be achieved by a generic level of clinical staff, with specialist staff providing advice and hands-on care as and when required"

(Director)

\section{Diagnostics and Pathology}

Diagnostic and pathology services were deemed by all managers to be essential parts of the supply chain. However while there is ongoing work at a national level to standardise diagnostic and pathology processes and to delineate clinical pathways for specific conditions, six managers believed that it would be difficult to challenge a Consultant's insistence on use of a different clinical pathway. One manager observed: 
"Professional practice is extremely difficult to tackle. If an orthopaedic surgeon insists on a standing knee X-ray, who am I to challenge this? Unless the clinical evidence shouts to the contrary, I'd rather spend time making sure the $X$ ray is done so the patient gets their operation” (Operations Manager)

It will help to clarify that the operations managers are not qualified surgeons and therefore, they cannot make decisions based on clinical evidence. Nevertheless, their key role is to micromanage the operations of the hospital.

\section{Pharmacy}

Pharmacy service was seen as fundamental to the supply chain. All managers believed that prescribing differences between consultants was now being actively managed by standardisation through internal committees and external guidance. Four managers described differences in prescribing practice between Consultants (funded through hospital drugs budgets) and GPs (funded through GP drugs budgets), including cases where patients are discharged on expensive drugs with questionable effectiveness, thus placing what might be regarded as an unwarranted ongoing strain on GP budgets. With an eye to 'business retention' or the lack of it, one manager warns that:

"If the GP isn't happy with Consultants prescribing expensive drugs with poor evidencebased effectiveness then they may encourage their patients to choose to go elsewhere" (Operations Manager)

\section{'Support Role’ Supply Chain Factors}

All managers agreed on the support role that specific factors such as bed availability, administration, facilities support (meals, cleaning, linen) and generic staff (porters, 
maintenance staff and non-specialised clinicians such as nurses and healthcare assistants) play. Whilst all managers described administration and finance as being the least important in the short term, all agreed there was a strong interdependence between supply chain factors. Perceptions on what constituted the most critical of these support factors varied. Four managers cited beds as being the priority factor, while the remainder described cleaning and the need for infection control as being the most important.

\section{IT systems support}

A common theme throughout most interviews was the frustration felt by managers at the lack of IT to support planning and supply chain management. One manager complained that:

"We were told to wait for a wonderful all-embracing nationally-procured IT system but that hasn't happened. We've sat still for three years" (Operations Manager).

As a result, systems were not standardised and were not able to link the elements of a patient pathway.

\section{(iii): After Elective Procedure}

All managers described an additional step in the patient pathway occurring after the operative procedure has been completed. Here, the Consultant team examines and 'signs off' the patient as no longer requiring acute hospital care. Thus the patient can be completely discharged, referred for rehabilitation (under a different medical team), or transferred to supported ongoing care. All managers agreed this was a significant point of change within the supply chain as ongoing care could then be provided but in a different setting. All managers pointed to the importance of discharge planning because of the adverse effect on waiting times if beds are not available. Additionally, five managers were concerned that inappropriate discharge would affect patient opinion of the hospital. Six managers in any event noted how supported discharge was very reliant on the capacity of community services. Thus, two 
Directors spoke of a willingness to purchase nursing home beds if necessary in order to maintain throughput. Local variability could thus have a direct impact on patient choice. As one manager observed:

"There are noticeable differences in lengths of stay for procedures nationally. This may affect choice; patients may wish to get back home quickly or they may opt for a hospital with a longer length of stay if community services are poor where they live” (Operations Manager)

Changes to the process mapping of hospital supply chains

Figure 3 shows the key components of the internal supply chain as agreed by the managers for the whole of the acute hospital supply chain where 'acute' implies treatment for short but severe illnesses, for conditions that result from disease or trauma, and for recovery from surgery. The acute phase sign-off has been added and all key components are drawn on the patient pathway where they have a key role in service delivery. No rehabilitation has been included in this process map as this is a separate stage in an elective procedure and could be undertaken at the hospital or at an alternative provider such as a nursing home or rehabilitation centre.

\section{"Insert Figure 3 About Here"}

Research Objective 3: To illustrate what hospital managers believe in terms of the potential impact of expanded Patient Choice on the hospital supply chain. Firstly, findings relating to current patient flows and healthcare supply chains are described. Then, some potential implications of expanded patient choice on future patient flows and supply chain management are explored. 
Current monitoring of patient activity flows

One manager noted the difficulty of trying to match demand with supply and stated: "Management of patient flows and the supply required in the hospital to undertake the procedures is always reactive. The knack is anticipating the demand fluctuations and managing this" (Operations Manager).

All three hospitals monitored outpatient activity in order to estimate admissions and related supply chain requirements. Thus, for example, the number of outpatient appointments acted as an analogue for the number of pre-operative assessments required. Monitoring was undertaken on a monthly basis with comparison made against historical trends and the Annual Capacity Plan. This information then helped plan theatre and operating schedules. All managers emphasised the importance of monitoring the Accident \& Emergency department activity in parallel as this generated between $20-40 \%$ of outpatient appointments. Two of the hospitals monitored appointment requests in some key specialties as a means of gaining a further two weeks notice of patient flow changes. But none of the four managers describing this system felt confident to estimate the accuracy of this predictive process. The majority of managers described the factors affecting internal supply management as not only being the activity flows per specialty, but also the complexity of the procedure to be undertaken (due to the high level of expertise required or ill-health of the patient). One Director cited success using strict allocation of activity slots to Consultants:

“The consultant cheque book enables clinicians to write 'cheques' for each planned procedure, with some differentiation between easy and complex procedures. Once they have finished their cheques, they are not able to book in any more patients until management have discussed internally or with commissioners to look for either extra capacity or extra funding" (Director) 
All directors and 2 managers expressed frustration at not being able to strip out supply chain factors in response to low demand fluctuations. This inflexibility was cited as being very costly to services management and appears to emphasise the interdependencies of the supply chain. As a Director explained:

"The supply system is so frustratingly inflexible. I wish the policy makers understood this. We could decide not to undertake a whole set of elective procedures but we can't take the costs out of the system.. .....Pharmacy, diagnostics and pathology all remain, at cost" (Director)

\section{Implications of Patient Choice on future activity flows and demand management}

All managers agreed that Patient Choice would create challenges for hospital supply chains. For one thing, they all felt strongly that the 18 -week maximum waiting time would have a significant impact in terms of the Patient Choice agenda given it would even out waiting times nationally. All managers felt that the outpatient department was still the appropriate place for activity monitoring of patient flows for hospitals. Five managers, however, expressed concern about a reliance on outpatient activity monitoring in future (even if compared to forecast activity) as this would only offer a reactive approach to managing patients choosing their hospital. At the same time, all managers expressed frustration at the lack of a comprehensive IT system by which to facilitate activity monitoring and predictive forecasting.

\section{Managing the supply chain differently}

The issue of managing the supply chain differently generated enthusiastic description of plans that appeared to have already been discussed within hospital management teams. The key themes are described below: 
a) No activity capping: Managers at all three hospitals made clear that they were committed not to stop any activity and to find capacity to undertake the procedures required, even if this meant sub-contracting to other providers in the short term. Two managers from different hospitals noted their preparedness to purchase 'step down' or nursing home beds if necessary in order to free up acute bed capacity. None of the managers interviewed felt that demand for their hospital services would rise significantly enough to be unmanageable.

b) Nurturing relations with GPs: Six managers across all hospitals highlighted a need to engage proactively with GPs. This proactivity was described as being on two levels i) on a clinician-to-clinician basis in order to 'market' a hospital's services and to enhance clinical networking and, ii) on a commissioner basis in order to work collaboratively around patterns of referral.

c) Developing Outpatient Services: Two hospitals were planning investment in outpatients in terms of physical environment and extra staff. All managers described plans for same-day outpatient, pre-operative assessment and admission appointment confirmation. As a director maintained: "Outpatients is so critical for patients to see as efficient. We are even considering running it as a loss leader, with additional staff and diagnostics to promote an efficient hospital reputation" (Director). The latter quote also illustrates how efficiency-driven is the modern NHS system and the fact that its managers do classify various aspects of the health provision based on profit or loss generation.

d) Dialogue with other acute hospitals: Two hospitals described plans to actively engage in sharing capacity with other local NHS acute hospitals. One hospital felt obliged to do this for capacity management purposes, offering out staff and theatres if /when the 
hospital had spare capacity and expecting reciprocal arrangements (although talks had not yet taken place). Managers at the second hospital described a relatively welldeveloped plan for a 'hub and spoke' model in regard to an acute NHS hospital 25 miles away where specialist consultant teams would be centralised in one hospital as the 'hub' offering services to the other as a 'spoke'. Such pragmatism implied that: "We need to swallow our pride and talk to other hospitals - it's going to be impossible on our own" (Operations Manager). The fact was that: "Even a 10\% drop in some specialties means that some of our services are not viable - Consultants won't be getting enough clinical experience to maintain their competencies. A hub \& spoke model with another hospital will enable us to maintain viability - and start pulling back tertiary care from specialist providers" (Director).

e) Annualised consultant contracts: All three Directors anticipated negotiations with consultants within the next twelve months for annualised contracts. All Directors felt this would create greater working flexibility that would help manage peak demand times.

\section{CONCLUSIONS \& RECOMMENDATIONS}

The empirical research reported on a number of factors that have the potential to influence patients when they choose a hospital for elective surgery, ranging from clinical performance to distance from a hospital. In general, these findings echo the work of the Department of Health (2006b), Rosen et al. (2007) and Appleby et al. (2003), amongst others. Nevertheless, one limitation of this element of the research is that these managers may have been influenced in their thinking by their pre-existing knowledge of the DoH national patient choice surveys. One new factor revealed in this research is the influence of the more stronglybranded hospitals on patients exercising choice. Thus, what may be anathema to some 
clinicians, steeped in a public service tradition while working to a largely centrally-driven supply paradigm - "branding" - comes to the fore as a potentially critical element for hospitals attempting to maximise throughput in a more competitive and demand-led era.

While waiting times were a significant factor for a number of researchers, the fact that there should be a standard 18-week target throughout the NHS in England for delivery of elective healthcare should, where met, effectively have removed this as a choice factor from 2008 . It remains unclear how patients may reprioritise other factors and this then requires further research.

From the discussions regarding components of a supply chain, additional factors have been added to the mapped supply processes and patient experience pathway. Components have been grouped into two main areas: those under the influence of the Consultant and those under the influence of management. From the research, it can be reasonably concluded that hospital managers anticipate some significant changes to their historical patient flows as Patient Choice expands. All hospitals demonstrate plans to protect their patient activity numbers; some by pro-active marketing and others by confidently maintaining their status quo and nurturing their local community.

The Hospital Supply Chain mapped in this research is original work, as there are no examples in the research literature specific to hospitals. Whilst in an embryonic stage, the mapping offers a starting point for other research. The key linkage to current research is the potential for integration of the patient pathway to healthcare pipelines (Towill \& Christopher 2005). This pathway begins to integrate the two concepts together, facilitating a shared understanding between hospital clinicians and supply chain managers.

What is not addressed, however, is the interrelatedness between emergency care and elective care. District hospitals struggle on a daily, sometimes hourly basis to manage capacity and 
demand at times of increased emergency admissions. An obvious solution would be to separate the two, perhaps even on different sites in order to minimise disruption to elective care. Nevertheless, emergency and elective care share specialist staff (for example, orthopaedic surgeons for traumatic bone injuries), expensive diagnostic equipment and intensive therapy units. This is not just a problem regarding economies of scale. Additionally, there is a knowledge supply issue in that clinical staff require the ongoing professional development of traumatic procedures in order to maintain their expertise.

The research offered insight into the plans and predictions of hospital managers at three Hospital Trusts of similar activity and size and the emergent thinking from managers linked key demographic factors to Patient Choice: for example, older people tend to choose their local hospital (Propper et al. 2006, Coulter et al. 2005, Rosen et al. 2007). Such an observation has practical implications, because if substantiated, it would enable some degree of risk assessment for hospital managers and commissioners. Hospitals shown to have high local elderly populations and may be less at risk of change to patient flows than those with younger populations. The frustration felt by managers regarding the inflexibility of their hospital supply chains was palpable in this work. The historic NHS culture of named Consultant beds and division of wards by speciality, coupled with inflexible clinical staff employment contracts, has helped ensure that supply chain management will continue to be very challenging as Patient Choice expands. This research found that hospital managers are beginning to recognise the need to manage networks with other hospitals in order to enhance flexibility of their supply chains because of the unpredictability of patient choice. This is a paradox: the creation of a competitive hospital market where patients can choose any provider may actually forge greater sharing of skills and supplies between hospitals!

Based on the findings of this research, we propose a set of recommendations for further research and policy action. 
1. Move to a managed competitive market: The government's NHS reforms have moved hospitals to an open competitive market. Thus, there are serious issues to be addressed in terms of whether hospitals can survive the competition from independent providers. For example, the independent sector may move to provide the more straightforward procedures for the NHS, i.e. to meet the demand for elective healthcare on relatively healthy patients who are unlikely to have complications and who will therefore have a short length of stay. In this scenario, the local NHS hospital will be 'left' with the more complex procedures and less healthy patients who have more complications and a longer length of stay. Hence, the NHS hospital's statistics and marketing appeal may look very poor against their independent counterparts. Patients may vote with their feet for the independent provider, and local NHS hospitals, with their inflexible supply chains, may not survive. Yet if this were to happen, who would provide the emergency care locally? It may well be prudent therefore for the government to seriously consider tempering this market, with a managed number of independent providers being able to compete with the NHS hospitals.

2. Establish a process for mapping hospital supply chains: there are many practical applications for the use of a comprehensively mapped hospital supply chain, particularly one that is understood by clinicians and operational management and centred on the patient. There needs to be a clearly established process for building such a map within every NHS Hospital Trust. The process map would link to the hospital's annual capacity and strategic five year plans and would have an ongoing, iterative process of renewal and adjustment according to new policies that affect it. This way, the learning is ongoing and the knowledge is embedded within organisations, available for use by hospitals and commissioners. This map could also be far more detailed and it could make use of the 
other Value Stream Mapping techniques mentioned in this paper to assist better managerial decision making.

3. Further research into demographic factors affecting patient choice: There remains an underlying suspicion that more affluent people might travel further to a hospital for treatment, whilst the elderly and those from deprived areas will go to their local hospital. This could create inequity in terms of real patient choice and has been highlighted by this research and others (Coulter et al. 2005, Propper et al 2006). Equal opportunity in terms of choice must therefore be closely monitored, to ensure that a two-tiered Patient Choice menu does not develop and everyone has the chance to choose their hospital.

4. Comprehensive information systems are urgently required: The NHS reforms currently being instigated represent profound changes to the market environment for hospitals and are being introduced at great speed, offering enormous challenges to NHS managers and commissioners. It almost beggars belief that these changes are taking place within an environment where the long-promised NHS enterprise-wide IT system remains elusive and piecemeal. Urgent decisions are required either to instigate this system in part on in whole as soon as possible, or to enable Trusts to procure their own systems and programmes.

5. There must be a stringent code of practice for marketing information from hospitals to patients: Managers are concerned about hospitals with strong branding having more power of persuasion over patients. The rising number of Foundation Trust Hospitals (with independent budgets) and the anticipated development of the hospital provider market means that in future there may be active marketing by hospitals for market share of NHS patients. When making a choice of hospital, patients currently remain dependent upon their GP (Rosen et al. 2007), but may become more influenced by attractive marketing information. This will require a very stringent code of practice in order to ensure that 
information is accurate and enables the patient to properly make their choice of hospital based upon reality, not rhetoric.

Last but not least, there are specific limitations emanating from this research. Specifically, we obtained views only from hospital managers and did not engage with other groups of actors of that supply chain such as clinicians and patients. In addition, our empirical research was restricted to only three NHS Hospital Trusts within two UK counties and from the same SHA. Further research could examine a larger number of hospitals and SHAs including other key actors of that supply chain such as clinicians and patients.

\section{REFERENCES}

Addicott, R. \& Ferlie, E. (2007) "Understanding Power Relationships in Health Care Networks" Journal of Health Organisation and Management, Vol. 21 No. 4/5, pp. 393-405. Appleby, J., Harrison, A., Devlin, N. (2003), What is the Real Cost of Patient Choice?' Kings Fund Publication, London

Bryman, A., Bell, E. (2003) Business Research Methods, Oxford: Oxford University Press Burge, P., Devlin, N., Appleby, J. London Patient Choice Project Evaluation - A Model of Patient's Choice of Hospital from Stated and Revealed Preference Choice Data Cambridge: Rand Europe, 2005

Christopher, M. (1998) Logistics and Supply Chain Management $3^{\text {rd }}$ edn, Pitman, London. Christopher M. \& Towill D.R. (2000) "Supply Chain Migration from Lean and Functional to Agile and Customised" Supply Chain Management: An International Journal, Vol. 5, No. 4, pp. 206-213.

Colletti, J. (1994) “Health Care Reform and the Hospital Supply Chain”, Hospital Materiel Management Quarterly, ; Vol. 15, No. 3; pp. 28-35. 
Coulter, A. LeMaistre, N., Henderson, L. (2005) Patient's Experience of choosing where to undergo surgical treatment - Evaluation of London Patient Choice Scheme, Picker Institute Publication

Dacosta-Claro, I. (2002) “The Performance of Material Management in Health Care Organisations", International Journal of Health Planning and Management, Vol.17, pp. 6985.

Department of Health (2000) The NHS Improvement Plan: Putting people at the heart of public services. London: The Stationary Office

Department of Health (2005) Payment by Results: Guidance London: The Stationary Office Department of Health (2006a) Choice at Referral - Guidance Framework for 2006/7, Department of Health Publications

Department of Health (2006b) National Patient Choice Survey; May, June, July, September; Department of Health Publications

Department of Health (2006c) Tackling Hospital Waiting: The 18 week Patient Pathway, an Implementation Framework London: The Stationary office

Fenies, P., Gourgand, M., Rodier, S. (2006) A Decisional Model for the Performance Evaluation of the Logistic Process: Application to the Hospital Supply Chain, ISMA, Campus Scientifique des Cezeaux, France

Gardner, J. \& Cooper, M. (2003) ‘Strategic Supply Chain Mapping Approaches’, Journal of Business Logistics, vol.24, No. 2, p37-52

Glaser, B.G. \& Strauss, A.L. (1967). The Discovery of Grounded Theory. Chicago: Aldine. Harland, C. \& Knight, L. (2001a) "Supply network Strategy: Role and Competency Requirements" International Journal of Operations \& Production Management, Vol. 21 no.4, pp 476-489 
Harland, C. \& Knight, L. (2001b). "Supply Strategy: A Corporate Social Capital Perspective". Research in the Sociology of Organizations, Vol.18: 151-183

Heinbuch, S. (1995) 'A Case of Successful Technology Transfer to Health Care', Journal of Management in Medicine, Vol. 9 No.2 pp 48-56.

Hines, P. and Rich, N. (1997), “The Seven Value Stream Mapping Tools”, International Journal of Operations and Production Management, Vol. 17, No. 1, pp. 47-64.

Isroliwala, S., Wainwright, C., Sehdev, K. (2004) A Local View of Factors Influencing Patient Choice, Cranfield University Publication Jarrett, P. (1998) 'Logistics in the Health Care Industry', International Journal of Physical distribution \& Logistics Management, Vol. 28, No. 9/10 pp. 741-772

Knight L., Harland, C., Walker, H., Sutton, R. (2005) 'Competence Requirements for Managing Supply in Interorganisational Networks, Journal of Public Procurement, Vol 5, No. 2, pp. 210-234

Kuljis. J., Paul, R., Lampros, P. and Stergioulas, K. (2007), Can health care benefit from modeling and simulation methods as business and manufacturing has?, in Proceedings of the 2007 Winter Simulation Conference S. G. Henderson, B. Biller, M.-H. Hsieh, J. Shortle, J. D. Tew, and R. R. Barton (Eds.).

McKone-Sweet, K., Hamilton, P. and Willis, S. (2005) “The Ailing Healthcare Supply Chain: A Prescription for Change", The Journal of Supply Chain Management, Winter. MacVaugh, T. (2007) “Complex Organisational Issues Require Complex Solutions” Hospitals Materials Management, April, Vol. 32, No. 4; pg.12

Mentzer, J. (2004) Fundamentals of Supply Chain Management; Twelve Drivers of Competitive Advantage, Sage, London

Miles, M., \& Huberman, A. M. (1994) Qualitative Data Analysis, $2^{\text {nd }}$ edn, London: Sage 
Minahan, T. (2007) “Can Supply Management Technology be the Antidote to the Healthcare Crisis?" Health Management Technology, Vol. 28, No. 9; pp.52-54

Page, B., Byrom, A. (2005) What Will People Choose when Choice goes live? MORI poll for Department of Health.

Propper, C., Damiani, M., Leckie, G., Dixon, J. (2006). ' Distance Traveled in England for Inpatient Treatment', CMPO Working Paper, University of Bristol

Rivard-Royer, H., Landry, S., Bealieu, M. (2002) 'Hybrid Stockless: A Case Study, International Journal of Operations \& Production Management, Vol. 22 No. 4, pp 412-424 Rosen, R., Florin, D., Hutt, R. (2007) An Anatomy of GP Referral Decisions - GPs Views on their Role in Supporting Choice, King's Fund Publication

Rhyne, D. (1988) ‘The Impact of Demand Management on Service System Performance', The Service Industries Journal, Vol.8, No.4; pp 446-458

Rother, M. Shook, J. (1998), Learning to See, The Lean Enterprise Institute, Brookline, MA.

Schneller, E., Smeltzer, L. (2006) Strategic Management of the Health Care Supply Chain, San Fransico: Jossey-Bass

Towill, D. \& Christopher,M. (2003) 'Designing Healthcare Delivery Systems', Conference Paper, Cardiff University, Wales

Towill, D., \& Christopher, (2005) 'An Evolutionary Approach to the Architecture of Effective Healthcare Delivery Systems', Journal of Health Organisation and Management, Vol. 19, No. 2, pp 130-147

Tyler, S. (2004) The Manager's Good Study Guide, Milton Keynes: Open University Press White, B. (2000) Dissertation Skills for Business and Management Students, London: Thompson 
Womack, J.P., Roos, D. \& Jones, D.T. (1990) The Machine that Changed the World, Macmillan Publishing Company.

Yin, R.K. (1984) Case Study Research; Design and Methods, London: Sage

Young, T. (2005), An Agenda for Healthcare and Information Simulation,

Management Science, Vol. 8, No. 3, pp.189-196

Young, T., Brailsford, S., Connell, C., Davies, R., Harper, P. and Klein, J. (2004) 'Using

Industrial Processes to Improve Patient Care”, British Medical Journal, Vol. 328, pp. 162-

164

http://www.labour-party.org.uk/manifestos/2001/2001-labour-manifesto.shtml (for Labour's manifesto, accessed 23/9/09). 


\section{TABLES \& FIGURES}

Table 1: Main activity data for each Hospital Trust

\begin{tabular}{|l|l|l|l|l|l|l|}
\hline $\begin{array}{l}\text { Hospital } \\
\text { No. }\end{array}$ & Budget & $\begin{array}{l}\text { No. } \\
\text { of } \\
\text { beds }\end{array}$ & $\begin{array}{l}\text { No. of first } \\
\text { outpatient } \\
\text { appointments } \\
\text { (first } \\
\text { attendance } \\
\text { for health } \\
\text { condition) per } \\
\text { annum }\end{array}$ & $\begin{array}{l}\text { No. of follow- up } \\
\text { (Subsequent } \\
\text { appointments for } \\
\text { ongoing treatment } \\
\text { or management) } \\
\text { outpatient } \\
\text { appointments per } \\
\text { annum }\end{array}$ & $\begin{array}{l}\text { No. } \\
\text { elective } \\
\text { procedures } \\
\text { per annum }\end{array}$ & $\begin{array}{l}\text { Managers } \\
\text { interviewed }\end{array}$ \\
\hline $\mathbf{1}$ & $£ 109 \mathrm{~m}$ & 295 & 56,741 & 110,225 & 39,021 & $\begin{array}{l}\text { Director, } \\
1 \text { operations } \\
\text { manager }\end{array}$ \\
\hline $\mathbf{2}$ & $£ 270 \mathrm{~m}$ & 796 & 93,000 & 170,000 & 73,000 & $\begin{array}{l}1 \text { Director, } \\
2 \text { operations } \\
\text { managers }\end{array}$ \\
\hline $\mathbf{3}$ & $£ 218 \mathrm{~m}$ & 706 & 91,500 & 198,600 & 75,400 & $\begin{array}{l}1 \text { Director, } \\
3 \text { operations } \\
\text { managers }\end{array}$ \\
\hline
\end{tabular}

Source: Annual Reports 2006/7

Figure 1: Draft Hospital Supply Chain Process Map for Elective Procedures

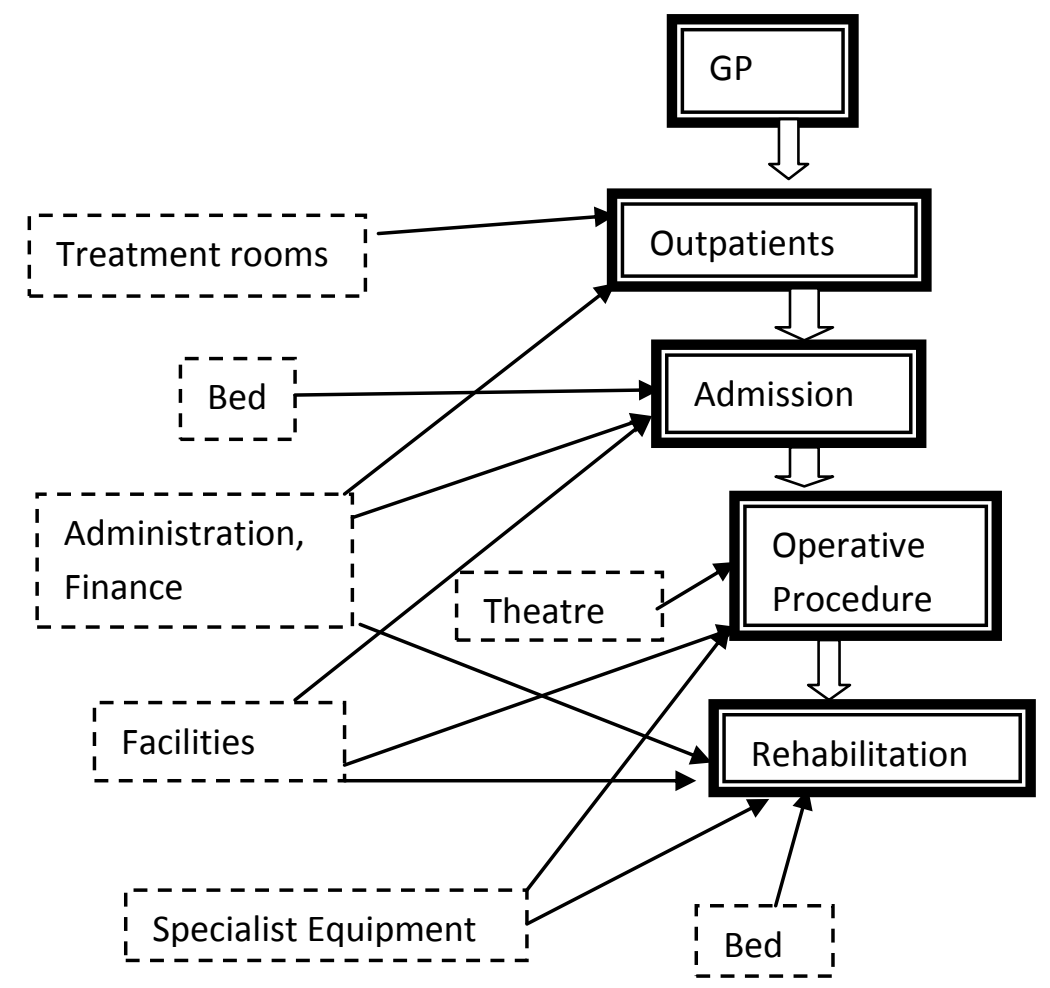

Consultant Led Team

Diagnostics

Pathology

Clinical Staff

Pharmacy 
Figure 2: Draft Hospital Supply Chain including Pre-admission detail

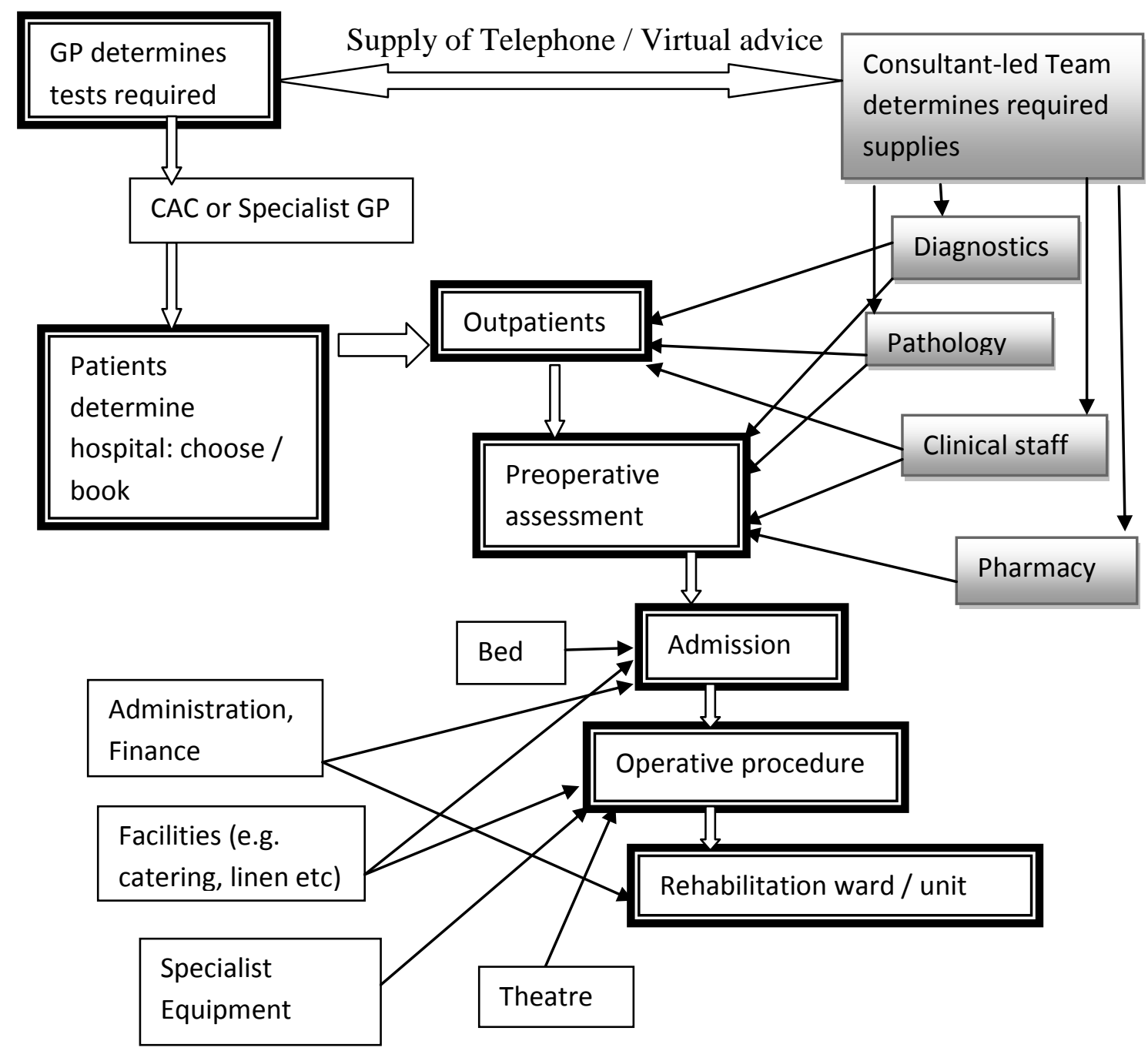


Figure 3: Hospital Supply Chain Process Map for Elective Procedures

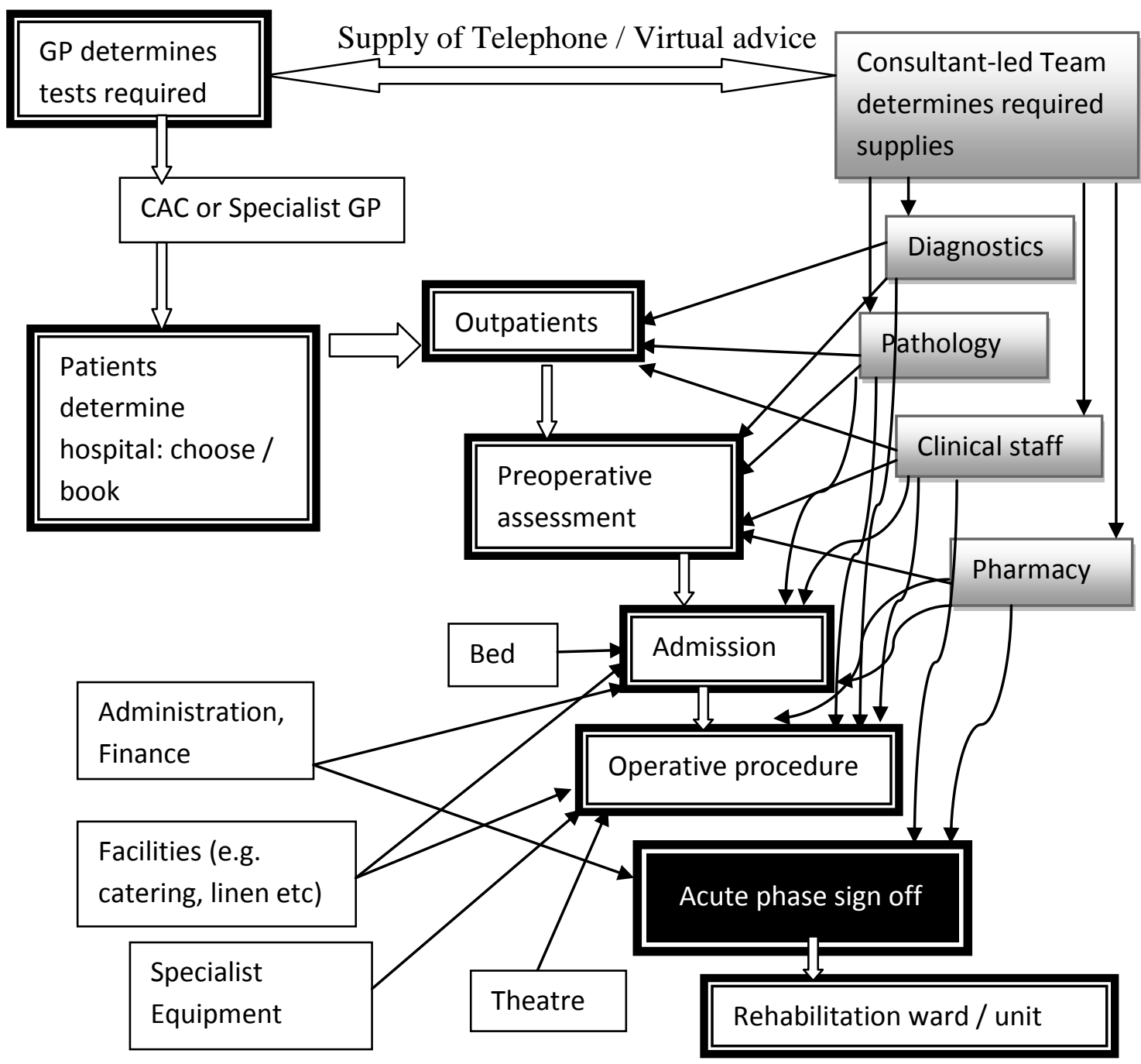

Note: The curved lines on the right part of Figure 3 and the black-coloured box (acute phase sign off) denote the new / extra activities taking place in comparison to Figure 2. 